\title{
Spatial discrimination learning in young chicks'
}

\author{
JAMES F. ZOLMAN AND DOUGLAS BECKER ${ }^{2}$ \\ UNIVERSITY OF KENTUCKY MEDICAL CENTER, DEPARTMENT OF PHYSIOLOGY, LEXINGTON, KENTUCKY
}

\begin{abstract}
Three groups of Vantress chicks $(22,45$, and $68 \mathrm{~h}$ old) were used to study the effect of age on acquisition of a spatial discrimination with heat as reinforcement. Only $50 \%$ of the oneday-old Ss reached criterion performance in 35 acquisition trials; whereas, $87 \%$ and $80 \%$ of the two- and three-day-old Ss, respectively, reached criterion (five successive correct choices). The one-day-old chicks made more errors and required more trials to learn the discrimination than the two older groups.
\end{abstract}

Newly hatched chicks cannot escape or avoid electric shock when tested in a one-way shuttle box, but are able to escape from shock the day after hatching. On the third hatch day, some chicks avoid shock, and by the fifth day most chicks can be avoidance trained (James \& Binks, 1963). Similarly, the very young chick (up to three days old) does not seem capable of acquiring a passive avoidance response; whereas, such a response is learned quickly when the chick is one week old. The ability to learn an approach response for warmth and food or brood mates is, however, present on the day of hatching (Peters \& Isaacson, 1963; Fischer \& Campbell, 1964).

While the development of escape and avoidance responses has been studied in many avian species, relatively little data exist on the ontogeny of discrimination learning in young birds (Sluckin, 1965). In this study, one- to three-day-old chicks were tested on acquisition of a spatial discrimination. Heat, recently found to be a reinforcer for young chicks (Zolman \& Martin, 1967), was used as reinforcement.

\section{Subjects}

The Ss were 47 Arbor Acre $x$ Vantress chicks incubated and hatched at $37-38^{\circ} \mathrm{C}$ and $85-88 \%$ relative humidity. Each $\mathrm{S}$ was banded and hatch time recorded within $1 \mathrm{~h}$ after emergence from the shell. Within $4 \mathrm{~h}$ after hatching, they were removed from the dark incubator and reared in groups of 15-20 in communal cages of a lighted $35^{\circ} \mathrm{C}$ brooder with food and water available ad lib. Sixteen Ss were tested on the day of hatching (21.9 h, SD 1.0); another $16 \mathrm{Ss}$ were tested the day after hatching $(45.1 \mathrm{~h}, \mathrm{SD} 1.9)$; and the remainder were tested two days after hatching (68.1 h, SD 3.3).

\section{Apparatus}

The apparatus was a discrimination box divided into a start box, choice area, and two goal boxes by guillotine doors $8 \mathrm{in}$. from the ends. The start box $(8 \times 6$ in.) and choice area were flat grey with screened grey tops. The two goal boxes (each $8 \times 7$ in.) were painted flat white, had open tops, and were separated from the choice area by two guillotine doors. The choice area extended 18 in. with a width of 6 in. near the start box and of $15 \mathrm{in.}$ at the goal boxes. The depth (11 in.) was the same for all parts of the apparatus. A raised 1 in. false floor of $1 / 4$ in. hardware cloth extended the length of the apparatus. The two goal boxes, separated by a 1 in. wall, were illuminated by a 16 in., 15-W fluorescent bulb located $2 \mathrm{ft}$ above the goal box floor. The choice area was illuminated dimly by the same light source. Heat was delivered by a 250-W, $115-\mathrm{V}$, red bulb infrared heat lamp located 21 in. above each goal box floor. The duration of the heat was controlled by a preset Universal timer activated by a hand switch when the $\mathrm{S}$ entered the correct goal box. All Ss were run in a dark Tyler temperature control room $(12 \times 7 \times 7 \mathrm{ft})$ set at $10^{\circ} \mathrm{C}$ with a fan providing masking noise. During the intertrial interval Ss were held in a grey $10^{\circ} \mathrm{C}$ cardboard box ( $6 \times 6 \times 6$ in.).

\section{Procedure}

Discrimination testing involved pretraining and acquisition of a spatial habit. Pretraining consisted of four trials in which the chicks were shaped to approach the white goal boxes to receive heat. On the first two pretraining trials, the $\mathrm{S}$ was placed in each goal box and given $15 \mathrm{sec}$ exposure to heat. On the last two pretraining trials, the $S$ was placed in front of each goal box and given heat after entering. Training trials began 30 sec after the pretraining trials. On a training trial the chick was held in the start box for $5 \mathrm{sec}$, the door then opened, and latency and initial choice recorded. A correction method was used and the $S$ was allowed to retrace or, after $60 \mathrm{sec}$, was guided into the correct goal box. The length of heat exposure was $15 \mathrm{sec}$ during training trials with a $30 \mathrm{sec}$ intertrial interval.

The chicks were given 35 trials to reach criterion (five successive correct choices). For one-half the Ss of the three age groups, the right goal box was correct; for the remainder the left goal box was correct.

\section{Results and Discussion}

As there were no significant differences among chicks required to go either right of left during acquisition, the data of these chicks were combined for each age group. Mean errors and trials to criterion for the groups are presented in Fig. 1. There were significant differences among the three age groups both in Errors $(F=6.91, \mathrm{df}=2 / 44, \mathrm{p}<.01)$ and Trials to Criterion $(F=8.29, \mathrm{df}=2 / 44, \mathrm{p}<.01)$. The oneday-old chicks made more errors and required more trials to reach criterion performance than the two older groups (Duncan's new multiple range test, $p<$ 


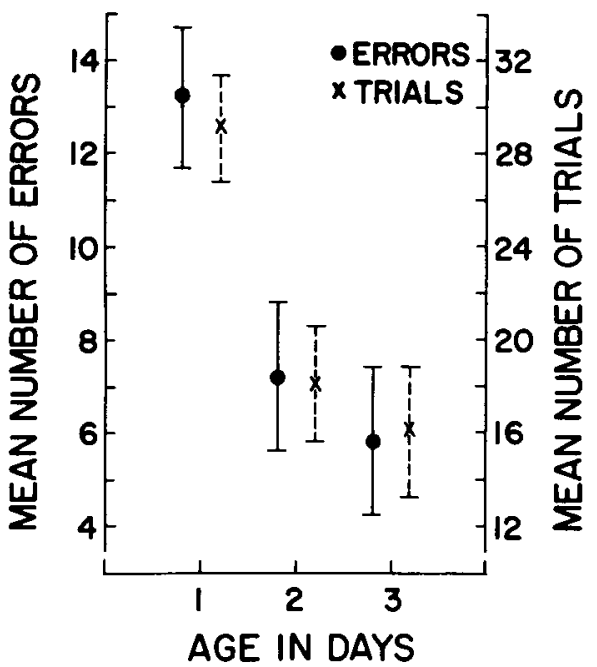

Fig. 1. Mean errors and trials to criterion for the three age groups (Bars are \pm standard errors).

$.05)$. Also, only $50 \%$ of the one-day-old chicks attained criterion performance; whereas, $87 \%$ and $80 \%$ of the chicks in the two- and three-day-old groups, respectively, reached criterion. Therefore, spatial learning in young chicks improved rapidly with age and was similar to the development of active and passive avoidance learning (James \& Binks, 1964; Fischer \& Campbell, 1964; Peters \& Isaacson, 1964).

The development of avoidance learning in the young chick has been suggested to be due to the maturation of neural mechanisms involved in fear (Fischer \& Campbell, 1964) and inhibition (Peters \& Isaacson, 1964). However, before age changes in performance can be attributed to maturational changes in neural mechanisms, it must be determined whether these age effects are caused by sensory, motor, or motivational changes. Essentially the same problems exist in ontogenetic research as those that exist in phylo- genetic comparison of learning ability (cf Bitterman, 1965). One problem is equating motivational levels of Ss of different ages. For example, newly hatched chicks are poor thermoregulators but rapidly develop thermoregulation the first week after hatching (Wekstein \& Zolman, 1967). Therefore, young chicks required to avoid passively a warm area or brood mates (a source of warmth) may not learn because of their high motivational levels. Older chicks with the ability to regulate their body temperatures would be able to learn to avoid a source of warmth (cf Fischer \& Campbell, 1964; Peters \& Isaacson, 1963). In our study, the oneday-old chicks may have had high motivational levels that were detrimental to their performance. Thus, these behavioral changes in the young chick could be caused by developmental increases in thermoregulatory ability. To determine the effect of temperature regulation on the preformances of different aged chicks would require testing all age groups under a variety of ambient temperatures (cf Zolman \& Martin, 1967).

\section{References}

BITTERMAN, M. E. Phyletic differences in leaming. Amer. Psychologist, $1965,20,396-410$.

FISCHER, GLORIA, J., \& CAMPBELL, G. L. The development of passive avoidance conditioning in leghorn chicks. Anim. Behav., 1964, $12,268-269$.

JAMES, H., \& BINKS, C. Escape and avoidance learning in newly hatched domestic chickens. Science, 1963, 139, 1293-1294.

PETERS, J. J., \& ISAACSON, R. L. Acquisition of active and passive responses in two breeds of chickens. J. comp. physiol. Psychol, 1963, 56, 793-796.

SLUCKIN, W. Imprinting and early learning. Chicago: Aldine Co., 1965.

WEKSTEIN, D. R., \& ZOLMAN, J. F. Homeothermic development of the young chick. Proc. soc. exptl. biol. Med., 1967, 125, 294297.

ZOLMAN, J. F., \& MARTIN, R. C. Instrumental aversive conditioning in newly hatched domestic chicks. Psychon. Sci., 1967, 8, 183-184. Notes

1. This research was supported by the Human Development Studies Program of the College of Medicine, University of Kentucky, with funds granted by the Foundations' Fund for Research in Psychiatry. 2. National Institute of Mental Health Summer Fellow, 1966. 